\title{
Governo das sociedades e compliance em Portugal: um escorço de sua delimitação histórico-normativa
}

\author{
Corporate governance and compliance in Portugal: \\ a foreshortening of its historical-normative delimitation
}

\author{
PEDRO TROVÃO DO ROSÁRIO'
}

prsosario@autonoma.pt

PAULO ROBERTO BARBOSA RAMOS ${ }^{2}$

paubr@uol.com.br

DAVID ELIAS CARDOSO CAMARA ${ }^{3}$

david.camara1@outlook.com

GALILEU - REVISTA DE DIREITO E ECONOMIA - e-ISSN 2184-1845

Volume XX $\cdot 1^{\text {st }}$ July Julho $-31^{\text {TH }}$ December Dezembro $2019 \cdot$ pp. 26-45

DOI: http://doi.org/10.26619/2184-1845.XX.2.2

Submitted on September 30 th $2019 \cdot$ Accepted on November 15 th, 2019

Submetido em 30 de Setembro, 2019. Aceite a 15 d eNovembro, 2019

RESUMO O presente trabalho tem como objetivo analisar o sistema jurídico português de combate à corrupção, com um estudo especial sobre compliance, seus marcos normativos e desafios no cenário global empresarial que preza cada vez mais por ferramentas eficazes de governo. Para tanto, serão analisados os marcos internacionais de mitigação de riscos, tais como o relatório Greenbury (1995), o Sarbenas Oxley Act (2004), e a lei brasileira n.12.846 (2013). Vez levantado um escopo histórico-normativo acerca do desenvolvimento de tais

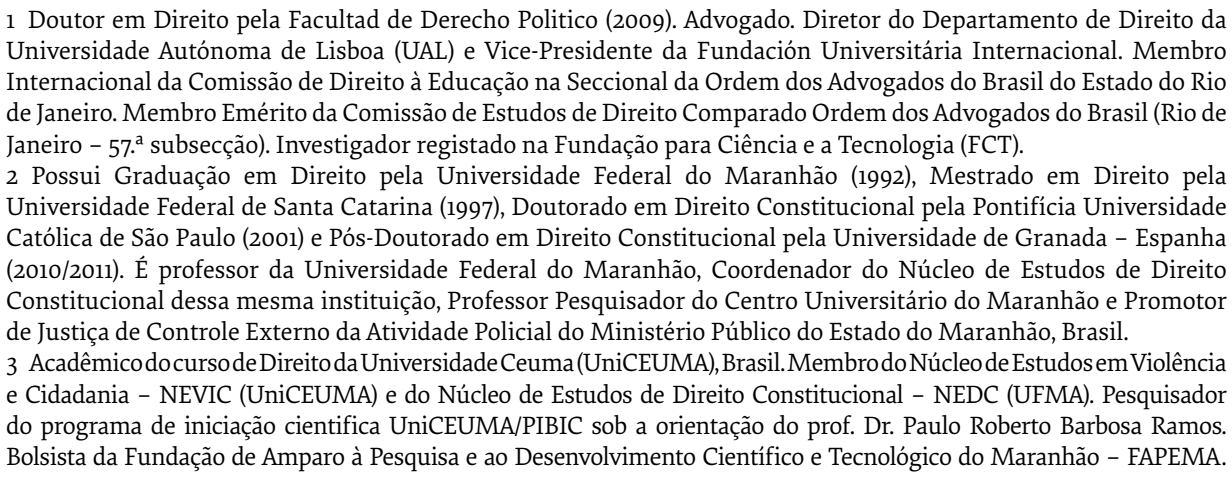


Governo das sociedades e compliance em Portugal: um escorço de sua delimitação histórico-normativa PEDRO TROVÃO DO ROSÁRIO | PAULO ROBERTO BARBOSA RAMOS | DAVID ELIAS CARDOSO CAMARA

GALILEU - e-ISSN 2184-1845 - Volume XX - Issue Fascículo 2 - 1st July Julho - 31 th December Dezembro 2019 - pp. 26-45

estruturas de combate à corrupção, será analisado se Portugal encontra-se em conformidade com o sistema internacional de governo das sociedades e de compliance.

PALAVRaS-ChaVE Governo das Sociedades. Compliance. Corrupção.

ABSTRACT This paper aims to analyze Portugal's structures of legality and corruption avoidance with a special look on compliance methods, its regulatory frameworks and challenges within a global corporate scenario that increasingly values government efficient tools. In order to achieve such purpose, it will be studied some international risk mitigation legal frameworks, such as the Greenbury report (1995), the Sarbenas Oxley Act (2004), and the Brazilian law n. 12.846 (2013). Once overcomed the historical-normative scope, it will be questioned whether Portugal is in fact aligned with the international system of compliance and corporate governance.

KEY WORDS Corporate Governance. Compliance. Corruption.

\section{INTRODUÇÃO}

Nas últimas três décadas, o debate a respeito da corrupção, da prevenção de riscos, da boa governança corporativa e do governo das sociedades intensificou-se a partir do surgimento de escândalos de corrupção envolvendo Estados de diferentes proporções e históricos, como o Reino Unido, os Estados Unidos e o Brasil - que tiveram que reestruturar os seus sistemas jurídicos de combate à corrupção, com a promulgação de normativos como, e.g., o relatório de Greenbury (1995), o Sarbenas Oxley Act (2004), e a lei n. 12.846 (2013).

De efeito, há um notável movimento global para o aperfeiçoamento e desenvolvimento de mecanismos para mitigação de riscos, tendo em vista que nenhum país está isento do fenômeno da corrupção.

No mundo, o debate a respeito do combate à corrupção adquiriu uma proporção inédita por parte dos agentes económicos, como empresas, investidores e a sociedade civil nas últimas décadas, tendo em vista que toda a coletividade, sem exceção, é prejudicada pelos efeitos mais nocivos das práticas desviantes como o enriquecimento ilícito, seja pelo branqueamento de capitais ou pela corrupção transnacional.

A par das atividades ilícitas no âmbito corporativo que corroem o tecido dos princípios da boa governança, da ética e da moralidade, iniciou-se um processo cooperativo entre os Estados para o enfrentamento de atos ímprobos, processo este que conta com a participação de atores supranacionais como Organizações Não Governamentais e Organismos Internacionais. 
A partir da década de 1990, em Portugal, foi possível assistir a uma mudança significativa em suas bases jurídicas para a mitigação e prevenção de riscos econômicos, principalmente pela constituição de órgãos de controles como a Comissão de Mercado de Valores Mobiliários (CMVM) - que possui legitimidade para fiscalização e controle de sociedades cotadas, e o Instituto Português de Corporate e Governance - que tem como objetivo a promoção e o desenvolvimento do governo das sociedades.

Tal cenário desenvolvimentista advém, principalmente, por parte do empresariado nacional e internacional que passaram a exigir regulamentos de maior proteção no setor empresarial, área mais vulnerada pela corrupção.

Todos estes marcos normativos de regulamentação possuem em comum medidas para a mitigação de riscos e combate à corrupção - objetivo central do governo das sociedades. Neste novo cenário de governo das sociedades, o empresariado e o Estado são os agentes de maior relevância e poder de atuação, tendo em vista que são possuidores de legitimidade para constituir práticas de boa governança nas áreas em que atuam.

Mais recentemente, uma nova ferramenta de proteção e prevenção veio à tona como aliado ao combate à corrupção: o compliance. Compreendido como um sistema empregado em uma empresa para alinhar um setor específico ou toda a organização dentro dos princípios éticos e morais da boa governança, o compliance surge a fim de mitigar as práticas criminosas amplamente debatidas no setor empresarial.

Apesar dos grandes esforços, contudo, é possível constatar que Portugal ainda se encontra em um processo de solidificação das referidas práticas de mitigação de riscos. Tal situação abre margem para discussões complexas sobre qual caminho o ordenamento jurídico português tende a seguir.

O presente artigo assim tem como objetivo geral, a partir de uma investigação histórica, examinar a evolução do governo das sociedades no combate à corrupção a nível global e analisar ainda tal desenvolvimento em Portugal, sob uma perspetiva essencialmente qualitativa - propondo um estudo entre os marcos legais de diferentes estados e seus respetivos mecanismos de proteção do capital e de governança corporativa.

\section{O governo das sociedades em Portugal: realidades e prospetos}

A globalização econômica levou a uma nova abertura do mercado de capitais aos investidores portugueses. A referida abertura econômica surge a partir da segunda metade do século XX, onde os nexos políticos, econômicos e sociais foram lesados no setor corporativo a partir das atividades criminosas advindas do fenômeno da derrubada de fronteiras 
comerciais, a exemplo da corrupção transnacional e do branqueamento de capitais, que, em síntese, têm como objetivo final o acrescimento patrimonial ilícito.

Assim, de modo a protegerem os seus interesses, os investidores internacionais passaram a exigir melhores e mais uniformizadas práticas de governança corporativa em Portugal, a partir da implementação das conhecidas políticas de segurança, integridade e transparência de capital, posto que o fenômeno da corrupção enquanto "problema social, estrutural, institucional e político, exige soluções igualmente estruturais" (BALLESTEROS, 2016, p. 23).

Portanto, o fator chave para o aprimoramento das práticas de boa governança não seria simplesmente superar a ausência de competência corporativa, mas sim, a superar a ausência de regulação voltada à redução de riscos em setores econômicos mais vulneráveis à corrupção.

Para tanto, é de suma importância que os estados em parceria com a sociedade civil e do empresariado, unam forças com o propósito de empregar e executar melhores normas de conformidade quanto a boa utilização de recursos públicos e privados.

Deste modo, a falta de políticas de combate à corrupção em tais setores econômicos permite que "se construa uma sensação de impunidade e, consequentemente, que se construa o fenômeno do abuso de poder econômico" (BALLESTEROS, 2016, p. 25).

Assim, a aplicação de medidas regulatórias de mitigação de vulnerabilidades promove, em tese, o processo de desenvolvimento econômico ao preservar os princípios da ética e moral no âmbito comercial, consequentemente, reduzindo eventuais insucessos no mercado devido a práticas de improbidade e possíveis processos devido aos atos de má-fé.

A este respeito, instaurou-se um novo momento de processo econômico e social voltados a mitigação de riscos advindos da corrupção, por meio do surgimento de normas, relatórios, comissões, instituições de controle, tratados internacionais e estudos voltados ao enfrentamento de atos nocivos a uma organização financeira.

O resultado prático da inserção das práticas de mitigação de risco é amplamente representado pelo chamado "governo das sociedades". Este sistema pelo qual as organizações financeiras são administradas e controladas mediante a supervisão de um ente regulador -revelam-se em uma "gama de ferramentas jurídicas e administrativas pelas quais os fornecedores e investidores de capitais são garantidos o retorno dos seus investimentos" (CUNHA, 2015, p.12).

Conhecido como Corporate Governance, ou simplesmente Governo das Sociedades ${ }^{4}$, esta teoria multidisciplinar abrange diversos campos de estudo, como a econômica, o direito

4 Em Portugal as agências de controle que possuem legitimidade para fiscalizar e executar as normas e diretrizes ao governo das sociedades atribuem diferentes nomenclaturas. De efeito, a Comissão do Mercado de Valores 
societário e o direito empresarial. De origem americana, a partir do emblemático estudo da “Teoria da Agência” de autoria dos economistas Adolph Berle e Gardnier Means, publicado em 1932, "o governo das sociedades tornou-se referência no estudo relacionado as medidas protecionistas no contexto corporativo". (PASSOS, 2017, p. 125).

Em meados da década de 1970, o governo das sociedades voltou a ser objeto de análise com a promulgação do Foreign Corrupt Practices Act (FCPA), pelo Congresso estadunidense, voltando a ser evidenciado em 2002, com o surgimento do Sarbenas Oxley Act (SOX) marco legislativo voltado ao combate à corrupção e branqueamento de capitais.

A partir de tais marcos iniciou-se um processo lento e gradual de cooperação internacional ao desenvolvimento e promoção do governo das sociedades. Para tanto, é de suma importância que os países constituam parcerias com o objetivo de constituírem regulamentos mais eficazes e sólidos de combate à corrupção.

Como explica Cunha (2012, p. 10): "À semelhança de outros crimes, a prevenção e repressão da corrupção impõe o reforço da cooperação internacional entre os Estados. Assim, se compreende que só uma perspetiva integrada do fenómeno da corrupção permitirá enfrentar esta ameaça e desenvolver adequadas ferramentas de prevenção e repressão".

Na União Europeia, por ilustrativo, o estudo do governo das sociedades iniciou-se em 1992 por meio do relatório Cadbury, "devido aos casos de fraudes e branqueamento de capitais envolvendo corporações do Reino Unido, como por exemplo a Marxwell, BCCI e a Mirror Group" (PASSOS, 2017, p. 128).

Em linhas gerais, o referido relatório modificou as estruturas de controle britânicas, reestruturando as ferramentas de mitigação de riscos, impondo, por exemplo, a necessidade de ser constituído uma área de auditoria interna no âmbito de toda pessoa jurídica empresarial.

Posteriormente, em 1995, surge o relatório Greenbury, com um caráter orientativo, que propõe às instituições financeiras situadas naquele mesmo país a constituição de uma relação entre os setores de administração e de transparência, promovendo, por exemplo, a divulgação das remunerações de seus funcionários, bem como dos sócios e investidores, por meio de relatórios anuais. Tal diretriz propõe também "a separação das funções de Presidente do Conselho de Administração e de Presidente da Comissão Executiva" (PIRES, 2008, p. 31).

Conforme explica Passos (2017, p. 128), "o relatório Greenbury redimensiona o cenário empresarial britânico quanto ao surgimento do princípio 'comply or explain', por esta 
as empresas devem declarar as normas que cumprem e justificar as situações de não-cumprimento".

Assim, inovações como essas levaram à ampliação do leque institucional britânico do combate à corrupção e a mitigação de riscos envolvendo instituições financeiras. Dessa forma, o Reino Unido redimensionou o cenário empresarial internacional no que tange a proteção do capital dos investidores.

Ao constituir assim uma efetiva cultura de boa governança corporativa com um víeis protecionista, este país foi elevado aos níveis de segurança quanto aplicação por parte de investidores e sócios, tornando-se referência no estudo de países que possuem um governo das sociedades realmente efetivo, posto que os riscos envolvendo atividades ímprobas no setor empresarial britânico são um dos menores, se comparados a nível global. ${ }^{5}$

A exemplo da experiência verificada no Reino Unido, outros países da União Europeia também desenvolveram marcos regulatórios com o intuito de salvaguardar o erário público e privado.

A Itália, por exemplificativo, promulgou em 1993 o Código de Comportamento dos Empregados das Administrações Públicas. O Código aludido prevê as regras de conduta, contratos e regulamentos com o objetivo identificar os comportamentos mais adequados à utilização do bem público. Já a França, em meados de 1993, instituiu sua respetiva lei sobre a prevenção da corrupção e a transparência da vida econômica.

Outro país europeu que reestruturou o seu sistema jurídico de mitigação de riscos foi a Espanha, em 1995, por meio da Lei n. 10, que criou o órgão denominado de Fiscalía Especial ou Fiscalía Anticorrupción, "membro integrante do Ministério Público espanhol com atribuição a repressão aos crimes econômicos relacionados à corrupção" (BLOCK, 2014, p. 14).

Assim, a nível intergovernamental, percebe-se através das palavras de Santos (2017, p. 29), que "há um movimento crescente de disseminação de iniciativas a favor do governo das sociedades".

Deste modo, a Organização para a Cooperação e Desenvolvimento Econômico (OCDE), a Organização dos Estados Americanos (OEA) e o Conselho da Europa (CE) podem ser destacados como exemplos de cooperação internacional ao combate as práticas criminosas no setor institucional financeiro posto que em suas atividades primárias, expedem orientações à boa governança empresarial.

Por ilustrativo, cumpre mencionar ainda a Convenção Interamericana contra Corrupção, como materialização deste crescente processo de ampliação do governo das socieda-

5 De acordo com o Transparency International (2018), o Reino Unido se posicionou na colocação de $11^{\circ}$ de 100 países menos corruptos. https://www.transparency.org/cpi2018; acesso em: 12/02/2019 
des. O referido marco, em seu texto, traz pontos importantes ao combate de atos de má-fé envolvendo o erário de uma instituição, estabelecendo a necessidade de regras de responsabilidade, de medidas que impeçam o suborno de funcionários nacionais ou estrangeiros.

Em 2003, de outro modo, a Organização das Nações Unidas (ONU) promulgou a Convenção Contra a Corrupção. O documento emitido por esta organização internacional, não obstante tenha força vinculante perante os membros signatários, na aceção de SANTOS (2017, p. 30), encontra sério problema e efetivação vez que "possui poucos mecanismos que garantam a aplicação de sanções por eventuais descumprimentos".

Diante dessa quadra, a ONU adotou uma série de diretrizes, como, por exemplo, a diretriz de n. 6, de políticas e práticas preventivas de corrupção, por seu turno, a de n.8 orienta para que os estados-membros constituam códigos de conduta para funcionários públicos.

Já em meados de 1999, a Organização para Cooperação e Desenvolvimento Econômico (OCDE) publica os Princípios de Governança Corporativa que, em seguida, foram atualizados em 2004 e revisados novamente em 2015. O documento é voltado para que os trinta e cinco Estados signatários da Convenção alinhem as suas instituições financeiras em conformidade com o governo das sociedades.

De acordo com Passos (2018, p. 132), os princípios mais relevantes são, em um primeiro momento, "assegurar a base normativa eficaz do governo das sociedades e a divulgação de informações, transparência e a responsabilidade civil, administrativa e penal dos agentes em conflito com as práticas de boa governança".

Neste sentido, a configuração moderna da relação entre Estado, pessoa jurídica empresarial e sociedade, já não se reduz aos ditames locais ou nacionais, nem tampouco às manifestações das instâncias formais do processo contra uma empresa.

Vive-se a era da democracia corporativa, em que o debate público amplo, realizado em contexto de livre circulação de ideias, de informações e medidas efetivas ao combate de toda e qualquer manifestação da corrupção, desempenha uma função racionalizada de desenvolvimento econômico.

\section{A comissão do mercado de valores mobiliários (CMVM) e o Instituto Português de Corporate Governance: breve histórico constitutivo e de sua atuação no modelo diretivo de governança corporativa}

Imerso no novo cenário do governo das sociedades e nas exigências do empresariado nacional e internacional, no que concerne a normatização e execução de mecanismos de mitigação de riscos, Portugal vem desenvolvendo instrumentos e práticas de boa governança, 
institucionalizando e reestruturando o seu ordenamento jurídico de combate à corrupção e mitigação de riscos econômicos.

Um exemplo prático da efetivação deste contexto no estado português, é a Comissão do Mercado de Valores Mobiliários (CMVM). Instituída em 10 de abril de 1991, pelo Decreto-Lei n. 142-A, a comissão é a instituição de controle com atribuições e competências para regular e supervisionar o mercado de valores mobiliários.

Sua função, em linhas gerais, é assegurar a proteção dos investidores, promovendo a eficiência, equidade, segurança e transparência do mercado de valores mobiliários. Nesse sentido, a CMVM que emite diretivas para instituições de mercado especificamente situadas em Portugal, é dotada de autonomia administrativa para a criação de comitês específicos de monitoramento nas mais diferentes áreas, como por exemplo, no setor de auditoria.

Esta comissão tem "competência na regulamentação e supervisão dos mercados de valores mobiliários e da atividade de todas as entidades, tanto públicas quanto privadas, que intervêm nesses mercados, sendo dotada ainda de autonomia financeira" (PASSOS, 2017, p. 132).

A especificidade do mercado imobiliário atrai a necessidade de maior regulamentação dada sua característica estratégica, do ponto de vista econômico, e dada sua vulnerabilidade.

Neste sentido, Jefferson Siqueira de Brito Álvares (2006, p. 154) muito bem esclarece no que consiste o mercado de valores mobiliários, e em que medida suas especificidades atraem melhor fiscalização:

[...] podem-se apontar os seguintes elementos cuja presença simultânea no mesmo instrumento financeiro o torna um valor mobiliário. Trata-se (a) da função econômica de instrumentar a captação de recursos para a consecução de empreendimento com fim lucrativo ou a obtenção de proteção contra riscos de variação de preços (hedge), (b) do risco potencial à poupança pública, (c) da negociabilidade e (d) da liberdade de forma. Com base nesses caracteres essenciais, é possível conceituar os valores mobiliários como instrumentos negociáveis de forma livre que instrumentam a captação de recursos para a consecução de empreendimentos com fim lucrativo ou a obtenção de proteção contra riscos de variação de preços (hedge), com risco potencial à poupança pública.

Em linhas gerais, referido mercado por ser compreendido como um mecanismo de distribuição de valores mobiliários que busca proporcionar uma maior proteção aos títulos emitidos por empresas e viabilizar seu processo de capitalização de recursos. 
No contexto português, as empresas pertencentes à bolsa de valores, corretoras e outras instituições financeiras participam do mercado mobiliário, contudo, estes "precisam estar em conformidade com as legislações locais e autorizadas pelo poder público" (Araújo, 2017).

As principais legislações que regulamentam o mercado de valores mobiliários português "estão presentes no Código dos Valores Mobiliários (CVM), aprovado em 13 de novembro de 1999, pelo Decreto-Lei n. 486 e ainda no Código das Sociedades Comerciais (CSC), aprovado em 02 de setembro de 1986 pelo Decreto-Lei n. 286" (CÂMARA, 2001, p. 14).

De acordo com Clotilde Passos, o Código dos Valores Mobiliários estabelece obrigações e sanções administrativas para as organizações econômicas abertas ${ }^{6}$, como, por exemplo, estabelecendo exigências quanto a prestação de informações do funcionamento da pessoa jurídica empresarial e de seus titulares, bem como quanto à transparência da identidade de seus investidores.

O Código das Sociedades Comerciais, noutro modo, é um instrumento normativo por meio do qual o governo português regulamenta o controle e a direção das instituições financeiras situadas no mercado português, embora não se restringindo às sociedades cotadas ${ }^{7}$.

Juntos, estes mecanismos de controle são possuidores de uma função social essencial para o funcionamento e caracterização de um mercado que preze pelo cumprimento de regulamentos a fim de mitigar riscos, evitando o comprometimento da integridade de empresas com condutas ilícitas, bem como, "fortalecendo a imagem de tais organizações perante a comunidade internacional, isto porque, as diretivas da Comissão do Mercado de Valores Mobiliários possuem um caráter essencialmente orientativo" (PASSOS, 2017, p. 135).

Essa espécie de soft law, que apenas pauta standards de governança corporativa, tem como objetivo oferecer uma maior liberdade de escolha ao empresariado em seu referido setor. Este grau de liberalidade permite aos agentes econômicos seguir os marcos orientativos da comissão, adaptando-os as especificidades e realidade econômicas de seu respetivo gênero de atuação.

A Comissão, que iniciou suas atividades ainda em 1991, emitiu as primeiras recomendações para as empresas cotadas e instituições financeiras emissoras de ações em mercado de valores, estabelecendo mecanismos de mitigação de risco de integridade que previam, por ilustrativo, a diretiva quanto a transparência em relação aos honorários pagos aos auditores e divulgação de informação obrigatória através de site na internet e, ainda, o "aperfeiçoa-

6 São consideradas sociedades de abertas as sociedades que têm capital disperso pelo público, nomeadamente as que tenham as suas ações admitidas à negociação num mercado de valores mobiliários regulamentado ou que tenham efetuado uma Oferta Pública de Venda (OPV) de mais de 10\% do capital

7 São consideradas sociedades cotadas aquelas em que o empresariado decide introduzir a sua empresa em bolsa de valores. 
mento da fiscalização interna na empresa, através, por exemplo, do sistema de auditoria interna" (PASSOS, 2017, p. 141).

Com efeito, diante das mutações econômicas do cenário internacional, e do novo cenário de gestão empresarial no início dos anos 2000, o Estado de Portugal realizou diversas alterações no Decreto-Lei n. 142-A, que instituiu a referida comissão.

Seguindo o estudo das revisões do Decreto-Lei n. 142-A, em novembro de 2003, houve uma nova revisão, por meio do regulamento n. 11, com o objetivo de normatizar os relatórios divulgados pelas empresas em Portugal. Em linhas gerais, a revisão teve como propósito atualizar o sistema de monitoramento, criando novos deveres de informações do mercado econômico.

Em meados de 2005 surgiram novas revisões para aperfeiçoar o sistema de fiscalização no setor empresarial português. Em 14 de abril de 2005, por meio do Regulamento n. 2, a CMVM passa a sugerir a criação de um gabinete de apoio ao investidor, o desenvolvimento de um sistema interno de controle para a deteção de riscos - com o objetivo de proteger e reduzir potenciais riscos devidos a condutas ilícitas, adoção de medidas para impedir o êxito de ofertas públicas de aquisição e o dever de respeitar os interesses das sociedades e seus acionistas.

O Decreto-Lei n. 142-A também veio sofrer novas edições a partir da constituição da Organização para o Desenvolvimento Econômico $(\mathrm{OCDE})^{8}$, da qual Portugal é membro integrante. Seguindo-se uma breve linha do tempo dos marcos regulatórios, já em 2007, as normativas já decretadas dão lugar ao primeiro Código de Governo das Sociedades em Portugal.

Em breve síntese, este documento visava alinhar Portugal aos novos ditames internacionais em relação ao governo das sociedades. Mediante o Regulamento de n.1, Portugal pela primeira vez emprega tacitamente o princípio comply or explain. Por este, as empresas devem "informar o grau de acolhimento das recomendações efetivadas pelo Código de Governo das Sociedades da CMVM e ainda o não amparo de tais diretrizes" (VICENTE, 2014, p. 14).

No ano de 2013 o estado português avança ainda mais no contexto do governo das sociedades. Por meio do Regulamento de n. 4 da CMVM, revoga-se o Regulamento de n.1 de 2010 e com o novo Código consagra-se a possibilidade de o empresariado português escolher um

8 Estas recomendações fazem parte do relatório da OCDE sobre princípios do Governo das Sociedades, que a OCDE publicou pela primeira vez em 1999 (Revista em 2004), depois de aprovado em conselho de ministros da OCDE. Este relatório assume grande relevância e passa a ser uma referência internacional para decisores políticos, investidores e outros intervenientes com interesses. Este assumiu tal importância, que o Fórum para a Estabilidade Financeira considerou que os Princípios da OCDE são uma das doze normas fundamentais para sistemas financeiros sólidos. 
código de governo das sociedades diferentes do da CMVM - condicionado, contudo, aos requisitos contidos em normas já estabelecidas.

Em termos gerais, o setor econômico de Portugal evoluiu com o surgimento do Regulamento de n. 4. Por meio deste, tanto os investidores nacionais como internacionais ficam mais livres em optar por um determinado sistema de controle o que consequentemente permitindo alinhar as empresas situadas no país ao âmbito internacional de competitividade.

Por fim, em 2018, o país reestruturou as bases do governo das sociedades, passando por uma transição para um modelo de autorregulação e recomendatório. A Comissão de Valores Mobiliários (CMVM), em parceria do Instituto Português de Corporate Governance (IPCG) lançam o Código de Governos das Sociedades do IPCG. Em linhas gerais, a nova legislação revoga o Código de 2013 da CMVM e se torna a única diretriz do Estado de Portugal para o empresariado situado no país.

Diante da análise evolutiva exposta, é possível constatar que o trabalho da Comissão do Mercado de Valores Mobiliários representa um considerável avanço na efetivação dos princípios éticos da governança corporativa.

Vez que Portugal demonstra adotar uma série de mecanismos institucionais a fim de estabelecer um ambiente de negócios antes de tudo justo e competitivo, torna-se claro perceber que as organizações institucionais não descuidam de padrões éticos e protecionistas diferenciados em termos de qualidade e conduta.

Mais do que um órgão de controle econômico, a Comissão de Mercado de Valores Mobiliários representa uma visão de maior competitividade para Portugal. Diante do novo cenário empresarial global que preza por um ambiente com menos corrupção e riscos para os sócios, investidores e consumidores, o país revela-se cada vez mais em sintonia com as necessidades de proteção da probidade e efetivação da justiça de mercado.

Certamente, revela-se fundamental na construção de um ambiente corporativo saudável e concorrente, a existência de uma instituição de controle que proporcione antes de tudo o diálogo entre os agentes econômicos.

Neste aspeto, ao perseguir formas de controles diversificadas das já instituídas com a Comissão de Mercado de Valores Mobiliários, Portugal ainda conta com as importantes contribuições do Instituto Português de Corporate Governance (IPCG) a luso ciência da governança corporativa.

Fundado em 2003, em breve síntese, o instituto tem por objetivo a investigação, divulgação e implementação dos princípios de Corporate Governance. Tal organização tem como base jurídica o direito privado e foi constituída mediante a associação sem fins lucrativos de desenvolvedores deste setor da ciência jurídica empresarial, dando ainda mais sustentáculo ao processo de estruturação e desenvolvimento do governo das sociedades. 
Diante da sua relevante missão institucional, é possível destacar a produção teórica sobre os conceitos e a prática do governo das sociedades. Por ilustrativo, em 6 de fevereiro de 2006, o IPCG lançou o Livro Branco sobre Corporate Governance em Portugal. O livro "aborda tópicos práticos do governo das sociedades, dedica algumas análises acerca dos códigos de um bom governo das sociedades, e as boas práticas de governança" (VICENTE, 2014, p. 21).

Já em 2013, o Instituto Português de Corporate Governance pública o seu Código de Governo das Sociedades. Diferente, este documento desenvolvido pela IPCG visa propor diretrizes para as sociedades abertas de Portugal, ao contrário das orientações de Governo das Sociedades efetivadas pela CMVM, que se restringia somente as sociedades cotadas.

Nos estudos de Vicente (2014, p. 22), "Tratou-se da resposta da sociedade civil à inexistência de um código de bom governo societário, não exclusivamente orientado para as sociedades cotadas, como é o caso do Código da CMVM".

Por fim, cumpre mencionar, que mais recentemente a Comissão de Valores Mobiliários (CMVM), em parceria com o Instituto Português de Corporate Governance (IPGC), constituíram um "Código do Governo das Sociedades". O novo Código visa amadurecer e desenvolver as estruturas jurídicas do Direito Societário de Portugal, por meio da regulação e supervisão da CMVM.

Em breve síntese, muito embora seja percetível a delineação de uma estrutura institucional da governança corporativa, de acordo com Clotilde Passos (2018, p. 68), "Portugal apresenta ainda uma evolução lenta no estudo e na promoção do Governo das Sociedades." Uma das razões elencadas por Passos para tal conclusão reflete na necessidade de "promover a efetiva prática de boa governança no setor empresarial do Estado".

\section{O compliance em Portugal: breve delimitação teórica}

A prática de corrupção existe desde a antiguidade como uma das formas mais problemáticas de violação aos direitos que os Estados enfrentam. Todavia, este cenário vem se transformando mediante as circunstâncias históricas, políticas, e socioeconômicas de modo que ao longo do tempo são notáveis as inúmeras mudanças da conduta pública e privada, especialmente quando se trata do uso de recursos financeiros.

No cenário internacional, desde a década de 1970, a corrupção tem obtido atenção especial, devido, principalmente, ao fenômeno da globalização econômica e, consequentemente, do surgimento da corrupção transnacional - definível como "processo de corrupção sistemática que vai além das fronteiras nacionais de um determinado ente soberano" (RAMINA, 2010, p. 21). 
Ante o estado de "corrupção globalizada", sobretudo entre agentes privados, desenvolveu-se um consenso no âmbito empresarial para a necessidade de elaboração de ações concretas de combate à corrupção.

Neste contexto, cumpre notar um dos mecanismos voltados ao combate da corrupção em nível transnacional, o compliance - instituído para prevenir, evitar, detetar e tratar qualquer desvio ou inconformidade devida à prática de corrupção.

Em breve síntese, referido mecanismo surge para contrapor a realidade de riscos e mitigar a eventual redução de potenciais investidores. Neste sentido, embora existam conceitos distintos acerca do significado da expressão "sistema de compliance", utiliza-se aqui a definição proposta por Block (2014, p. 85), para quem "significa agir de acordo com uma regra, uma instrução interna, um comando ou um pedido".

Dessa forma, estar em compliance significa que a pessoa jurídica pública ou privada está em conformidade com as exigências legais e regulamentares no âmbito corporativo que atua.

Além do compliance, o programa de integridade também inserido na lógica preventiva do combate à corrupção, é considerado importante mecanismo de combate à corrupção.

Aplicado primeiramente por meio do Foreign Corrupt Practices Act (FCPA), em decorrência do emblemático caso Watergate, o referido programa consiste no conjunto de procedimentos internos de integridade, auditoria e incentivo à denúncia de irregularidades e na aplicação efetiva de códigos de ética e de conduta, políticas e diretrizes com objetivo de detetar e sanar desvios, fraudes, irregularidades e atos ilícitos praticados no âmbito das pessoas jurídicas públicas ou privadas.

Outro notável mecanismo pioneiro de prevenção às práticas criminosas em âmbito financeiro, foi instituído através do UK Bribery Act, no Reino Unido. Com um "caráter punitivo contra qualquer ato de suborno perante administração pública" (GEWEHR, 2014, p. 24), a norma em questão, assim como o FCPA, estabeleceu uma quadra capaz de desenvolver a aplicação conjunta de diretrizes voltadas à rede global de mitigação de riscos econômicos.

Neste mesmo sentido segue a Lei n. 12.846/2013 - denominada de Lei Anticorrupção ou Lei de Empresa Limpa, que integra o quadro normativo internacional da prevenção e combate à corrupção, "reestruturou o sistema normativo brasileiro estabelecendo standards de prevenção e mitigação de riscos à pessoa jurídica envolvida em casos de corrupção" (BLOCK, 2014, p. 88).

Este novo regulamento foi capaz de alinhar o Brasil ao sistema internacional de países que buscam uma cultura corporativa e de cumprimento das leis e regulamentos, objetivando assim, a elaboração de padrões éticos em âmbito empresarial. 
A partir da análise de tais marcos normativos, é possível observar ser de extrema importância a regulamentação de exigências que cessem ou ainda mitiguem a prática de atos de corrupção, estabelecendo assim, estruturas normativas contra atos de improbidade que ao mesmo tempo permitam a prevenção de danos econômicos e estimulem a transparência e as boas práticas corporativas.

Isso porque a adoção destes mecanismos não somente viabiliza a criação de um sistema econômico saudável como ainda permite, um crescimento estratégico da economia.

Neste aspeto, a Organização das Nações Unidas (ONU), estima que " $5 \%$ do PIB mundial é branqueado" (ONU, 2013, p. 2), sendo capaz de desincentivar a aplicação de capital de investimento, especialmente em países notáveis por sua corrupção sistêmica.

Assim, o estado que não se alinhar a estas novas exigências, estará um passo atrás do mercado, tendo em vista que os investidores estão mais cuidadosos quanto aplicação de seu capital.

Diante deste contexto, no qual destacaram-se as inovações normativas levadas à cabo por Estados Unidos, Reino Unido e Brasil, destaca-se ainda o sistema legal português de prevenção e combate à corrupção.

Como ilustrativos, cumpre notar a Lei n. 34, de 15 de julho de 1987, que apesar de não estabelecer instrumentos de prevenção, tem como escopo "a responsabilização penal e civil de titular de cargo político e de alto cargo público que, em abuso de função ou grave desvio de interesses, e.g., prevaricar, solicitar ou aceitar vantagem patrimonial ou não patrimonial, que não lhe seja devida, ou ainda praticar qualquer ato ou omissão contrários aos deveres do cargo em virtude de vantagem indevida" (CUNHA, 2015, p. 17).

Demais, destaca-se ainda a Lei n. 5 de 11 de janeiro de 2002 que, em linhas gerais, cria um regime especial de recolha de prova, quebra de segredo profissional e perda de bens em favor do estado para diversos crimes advindos de corrupção.

Em 21 de abril de 2008, também, surge a Lei n. 20 que prevê a responsabilidade penal das pessoas coletivas e individuais por corrupção no setor privado e a corrupção com prejuízo do comércio internacional.

Posteriormente, é aprovada em 5 de junho a Lei de n. 25 de 2008, que estabelece medidas de natureza preventiva e repressiva de combate ao branqueamento de capitais advindas de ato ilícito e ao financiamento do terrorismo. Seguindo a linha do tempo dos marcos regulatórios ao combate à corrupção em Portugal, em 4 de setembro de 2008 a Lei de n. 54, que cria o Conselho de Prevenção da Corrupção.

Diante da legislação em apreço, é possível classificar o sistema normativo português de combate à corrupção em duas grandes áreas: uma, que tem o objetivo de criar normas que facilitem a relação dos cidadãos com a utilização da administração pública ou que também 
criam exigências éticas em âmbito corporativo, como, por ilustrativo, o comply or explain, e procedimentos administrativos transparentes; e outra, que instituída pelo código penal, tem o objetivo de dissuadir o crime.

Não obstante o histórico de leis anticorrupção datar desde a década de 1980, a "adoção do sistema de compliance em Portugal, tem pouco mais de uma década de efetivação" (PASSOS, 2014, p. 46). Com efeito, o país apresenta atrasos ${ }^{9}$ em relação aos demais estados-membros da União Europeia no que contempla medidas de prevenção e controle das práticas de corrupção no âmbito empresarial.

Apesar de tal constatação, o país ibérico possui arrojadas ferramentas de mitigação de riscos. Um exemplo capaz de ilustrar tal afirmação consiste na Comissão do Mercado de Valores Mobiliários (CMVM).

A comissão, instituída em 10 de abril de 1991 pelo Decreto-Lei n. 142-A, é a organização que possui legitimidade para regularizar os códigos de integridade empresarial e, assim como, supervisionar funcionamento dos mercados de valores mobiliários e a atividade das instituições públicas e privadas que possuem atuação no território lusófono.

São ainda atribuições da Comissão de Valores Mobiliários ${ }^{10}$ :

Sancionar as infrações ao Código dos Valores Mobiliários e legislação complementar; Assegurar a estabilidade dos mercados financeiros, contribuindo para a identificação e prevenção do risco sistémico; Contribuir para o desenvolvimento dos mercados de instrumentos financeiros; Prestar informação e tratar as reclamações dos investidores não qualificados; Proceder à mediação de conflitos entre entidades sujeitas à sua supervisão e entre estas e os investidores; Coadjuvar o Governo e o respetivo membro responsável pela área das Finanças(...).

Ou seja, como se verifica, Portugal atribuiu a CMVM sendo a organização reguladora de instituições empresariais públicas e privadas situadas no país. Contudo, ainda que inserida em uma estrutura organizacional hierarquizada na qual é submetida às esferas de decisão superior, esta organização possui autonomia administrativa para criar normas e exercer seu papel fiscalizador no âmbito do mercado de valores.

9 A este propósito, vale a pena destacar um estudo realizado pela Heidrick e Struggles acerca do Corporate Governance na Europa, onde se constata o referido atraso na dimensão que se reporta à análise dos órgãos de administração das empresas, o rating encontrado para Portugal foi o mais baixo.

10 As atribuições da Comissão de Valores Mobiliários encontra-se no sítio eletrônico da própria instituição de controle portuguesa: https://www.cmvm.pt/pt/CMVM/Apresentacao/Pages/Apresentacao-o-que-e-a-CMVM. aspx. 
Neste aspeto, o empresariado português vê uma problemática, tendo em vista que a Comissão de Mercado de Valores Mobiliários se apresenta como a única organização de controle no setor de fiscalização das sociedades cotadas no país.

Fazendo com que restrinja o investimento econômico por parte de potencias investidores, já que as instituições financeiras não cotadas nas bolsas de valores portuguesas não são contempladas pelo Código da CMVM.

Diante deste quadro, em 1 de fevereiro de 2010, a CMVM publicou o Regulamento n.1, que "veio reconhecer as empresas o direito de optarem por um código de governo diferente daquele que foi emitido pela Comissão" (SANTOS, 2017, p. 77).

Assim, nas palavras de Miguel Vicente (2014, p. 32), "trata-se da resposta da sociedade civil à inexistência de um código de bom governo societário, não exclusivamente orientado para as sociedades cotadas".

Nesse sentindo, redimensionando o quadro normativo de Portugal na relação de imposição quanto a implantação do código de ética nas pessoas jurídicas e, alocando a dita questão para o empresariado português quanto a opção de implantar ou não mecanismos de integridade na pessoa jurídica.

Com efeito, a partir dessa transição impositiva, para uma questão optativo do governo de Portugal, este novo cenário empresarial vai no sentido de maior regulamentação e liberdade dada ao mercado econômico em unir forças como o Estado para o combate às fraudes.

Portanto, a política adotada por Portugal se assemelha com as novas mudanças que vem se operando a nível da União Europeia, Estados Unidos e Brasil, que a tendência é para recorrer às recomendações, em vez de obrigações - o objetivo essencial do compliance.

\section{CONCLUSÃO}

Os atos atentatórios que vão de encontro aos princípios do Governo das Sociedades, envolvendo de sobremodo o branqueamento de valores e a corrupção transnacional - levados à cabo pelo intenso processo de abertura do mercado de capitais no novo cenário de globalização econômica, são fenômenos cada vez mais objeto de atenção por parte dos estados nacionais e da sociedade civil organizada.

Seja porque o fenômeno da corrupção enquanto problema social e estrutural, exige-se soluções igualmente estruturais, seja porque ainda é capaz de fulminar o pleno desenvolvimento dos agentes econômicos, certo é que novas estratégias de regulação voltada à redução de riscos em setores econômicos mais vulneráveis à corrupção é uma realidade atual encorajada por todos aqueles comprometidos com o desenvolvimento de um mercado justo. 
Tais estratégias podem ser precisamente delineadas no âmbito normativo, a partir da análise dogmática da legislação econômica dos países, e ainda na difusão de mecanismos de controle, monitoramento e de combate à corrupção.

Em termos de revisão normativa, são destacáveis os marcos legais de corporate governance apresentados nos Estados Unidos, Reino Unido e Brasil, como, e.g., o relatório de Greenbury (1995), o Sarbenas Oxley Act (2004), e a lei n.12.846 (2013) que constituíram uma efetiva cultura jurídica de boa governança corporativa com um víeis essencialmente protecionista.

Já os mecanismos institucionais de controle e monitoramento podem ser ilustrados objetivamente em setores governamentais e não governamentais como, e.g.,a Organização para a Cooperação e Desenvolvimento Econômico (OCDE), a Organização dos Estados Americanos (OEA) e o Conselho da Europa (CE). Tais organismos, que expedem orientações à boa governança empresarial, podem ser destacados como exemplos de cooperação internacional no combate as práticas criminosas no setor financeiro.

Em que pese possam apresentar estágios particulares de aplicação das técnicas de governança corporativa, todos estes países possuem algo em comum: todos tiveram em algum momento que se deparar com a problemática da corrupção em suas instituições econômicas, seja no setor privado ou público.

O Governo das Sociedades surge assim para estabelecer ambiente mais seguro para os investidores e a sociedade civil, tendo em vista que a sua atuação envolve principalmente setores vulnerados pela corrupção, por exemplo, a economia, o direito societário e o direito público.

O seu caráter orientativo surge com o objetivo de proteger os interesses dos stakeholders, por meio da gestão e ferramentas de controles mais rigorosas e eficientes contra os atos criminosos que possam ocasionar qualquer dano ao erário da pessoa jurídica pública ou privada. Visa ainda, a transparência das ações financeiras e, assim, como a responsabilização dos órgãos da Administração.

Mais recentemente surge o Compliance. No contexto corporativo, a adoção de tal mecanismo significa um maior grau de proteção para os investidores, tendo em vista que o emprego deste mecanismo de prevenção busca, também, melhorar a atuação da empresa em seu respetivo setor, evitando, assim, processos civis e administrativos que podem colocar em risco os negócios e aplicações.

O emprego deste mecanismo, por oportuno, não somente viabiliza a criação de um sistema econômico saudável, pautado nos princípios éticos e morais da boa governança, como ainda permite um crescimento estratégico da economia, ao passo que o empresariado 
internacional busca investir o seu capital em países com melhores graus de segurança e combate à corrupção.

Em Portugal, o sistema de Compliance é constituído, ainda que indiretamente, por meio da Comissão de Mercado dos Valores Mobiliários (CMVM) e do Instituto Português de Corporate Governance (IPCG).

Com efeito, por mais que tais organizações de controles sejam competentes na fiscalização e regulamentação do empresariado português bem como na elaboração de orientações e diretrizes à mitigação de riscos e práticas de boa governança, Portugal ainda não reconhece o programa de compliance expressamente, posto que não detém de um marco normativo que defina tal conceito e unifique sua aplicação sobre os agentes econômicos sob sua jurisdição.

Gradualmente, porém, o país lusitano vem se estruturando organizacionalmente para o novo cenário internacional de práticas de mitigação de riscos, mas a evolução ainda é pequena se comparada à nível global.

A aplicação de um programa de prevenção e mitigação da corrupção, como o compliance, nas empresas deixou de ser uma questão optativa, mas sim, uma perspetiva de necessidade e universal para os Estados que quiserem prosperar no mercado econômico.

\section{REFERÊNCIAS}

ÁLVARES, Jefferson Siqueira de Brito. O Atual Conceito de Valor Mobiliário. In: Revista de Direito Mercantil, Industrial, Econômico e Financeiro, n. 142, abr./jun. 2006

ARAÚJO, Alan Pereira de. A CVM e a Taxa de Fiscalização dos Mercados de títulos e Valores Mobiliários. In: Revista da AGU, vol. 17. n. 2. abr./jun. 2018

BALLESTEROS, Irma Eréndira Sansoval. Enfoque de la corrupción estructural: poder, impunidad y voz ciudadana. In: Revista Mexicana de Sociología; vol. 78. n. 1, ene. /marzo 2016

BLOCK, Marcella. Nova Lei Anticorrupção (Lei 12.846/2013) e o Compliance. In: Revista de Direito Bancário e Mercado de Capitais. Vol. 65. 2014.

BRASIL. Lei n. 12.846, de 1. de agosto de 2013. Disponível em: < http://www.planalto.gov.br/ccivil_03/_ ato2011-2014/2013/lei/l12846.htm.>. Acesso em 02 Fev. 2019.

CÂMARA, Paulo. O Governo das Sociedades em Portugal: Caderno do Mercado de Valores Mobiliários. 12. 2001

CUNHA, Ary Ferreira. Combate à corrupção: da teoria à prática. Lisboa: Quid

ESPAÑA. Ministerio de la Presidencia, relaciones Con Las Cortes e Igualdad. Fiscalia Organizad. Disponível em: < https://www.boe.es/buscar/doc.php?id=BOE-A-1995-10066

FRANCE. Legisfrance. la prévention de la corruption et à la transparence de la vie économique et des procédures publiques de 1994. Disponível em: https://www.legifrance.gouv.fr/affichTexte. do;jsessionid=0535B92AF63FoF2BA4E4A24D6FB32B8A.tplgfr25s_1?cidTexte=JORFTEXToooooo 7 $11604 \&$ dateTexte $=20090716>$. Acesso em 16 Fev. 2019. 
GEWEHR, Elson Dérin. Compliance na Gestão de Fundos de Investimento. Dissertação (Dissertação em economia). UFRGS Rio Grande do Sul. 2011.

GOVERNANCE, Instituto Português de Corporate. Livro Branco Sobre Corporate Governamental em Portugal, 2006. Disponível em: < http://www.ecgi.org/codes/documents/libro_bianco_cgov_pt.pdf>. Acesso em 26 Jan. 2019

GOVERNANCE, Instituto Português de Corporate. Cadernos do IPCG (2001) Sobre Corporate Governance Boas Práticas dos Órgãos de Administração das Sociedades 1. ${ }^{\circ}$ fascículo 26 de Abril de 2011. Acesso em 27 Jan 2019.

GOVERNANCE, Instituto Português de Corporta. Código de Governo das Sociedades, 2018. Disponível em: https://cgov.pt/images/ficheiros/2018/codigo-pt-2018-ebook.pdf Acesso em: 05 fev. 2019

HEIDRICK \& STRUGGLE. Is Your Board Fit For the Global Challenge? Corporate Governance in Europe. Disponível em: <http://www.heidrick.com/NR/rdonlyres/DACDA5Co-7DD5-4A8DAE86-A50Ao1CFCD57/o/HS_CorpGovEurope.pdf >. Acesso em 14. Fev. 2019.

INTERNACIONAL, Transparency. Corruption Perceptions Index. Disponível em $<$ https://www.transparency. org/cpi2018>. Acesso em: 24. Jan, 2019

ITALIA. Presidenza del Consiglio del Ministri Dipartimento Della Funzione Pubblica. Codice di comportamento dei dipendenti delle pubbliche amministrazioni de 1993- Disponível em: <http://www. beniculturali.it/mibac/multimedia/MiBAC/documents/1375440149998_Codice_di_comportamento_ dei_dipendenti_delle_pubbliche_amministrazioni.pdf $>$. Acesso em: 16 Fev. 2019.

, Recomendações da CMVM sobre o Governo das Sociedades Cotadas, Nov. 2003. Disponível em <http://www.cmvm.pt/recomendacoes_e_orientacoes/recomendacoes/soccot_nov2003/indice.asp>. Acesso em 22 Jan. 2019.

MOBILIÁRIOS, Comissão do Mercado de Valores. Recomendações da CMVM sobre o Governo das Sociedades Cotadas. Disponível em: < http://www.cmvm.pt/pt/Legislacao/Legislacaonacional/ C\%C3\%B3dGoverno\%2odas\%20Sociedades/AnexosGovSoc/Pages/99_indice.aspx>. Acesso em 22 Jan. 2019.

MOBILIÁRIOS, Comissão do Mercado de Valores. O que é a CMVM? Disponível em: <https://www.cmvm. pt/pt/CMVM/Apresentacao/Pages/Apresentacao-o-que-e-a-CMVM.aspx>. Acessp em 24 de Jan. 2019.

OCDE, principles of Corporate Governance. 1991. Disponivel em: http://www.oecd.org/daf/governance/ principles.htm. Acesso em 30 Jan. 2019.

ONU. Convenção Contra Corrupção. 2003. Disponível em:<https://www.unodc.org/unodc/en/treaties/ CAC/>. Acesso em: 16 Jan. 2019

ONU. Corrupção e desenvolvimento. 2013. Disponível em: < http://www.unodc.org/documents/lpo-brazil/ Topics_corruption/Campanha-2013/CORRUPCAO_E_DESENVOLVIMENTO.pdf>. Acesso em: 16 jan, 2019.

PASSOS, Clotilde. Governo das Sociedades - Diagnóstico da Situação em Portugal. In: Revista Gestão e Desenvolvimento, n. 25. 2017.

PIRES, Ana Isabel Marinho. Impacto da Lei Sarbanes - Oxley no Sistema de Controle Interno das empresas cotadas nos EUA - O caso Português; Mestrado em Contabilidade e Auditoria; Universidade Aberta. 2008.

RAMINA, Larissa. A Convenção Interamericana Contra a Corrupção: uma breve análise. In. Revista Direitos Fundamentais \& Democracia. Vol. 6. 2008.

SANTOS, Diogo De Almeida Viana Dos. Compliance e Legislação Anti-Corrupção: Uma perspectiva Comparada. In: Revista Brasileira de Filosofia do Direito, Vol. 4. n. ${ }^{\circ}$ 1. 2018. 
UK Foreign Bribery Strategy. Londres, 2015. Disponível em: <http://webarchive.nationalarchives.gov. uk/20121205231543/http://www.officialdocuments.gov.uk/document/cm77/7791/7791.pdf >. Acesso em: 14 Jan. 2019.

UNITED STATES. Foreign Corrupt Practice Ack. Washington, abr. 1977 Disponível em:<

https://www.justice.gov/sites/default/files/criminal-fraud/legacy/2012/08/29/corruptrpt-95213.pdf >. Acesso em: 30 Jan. 2019.

VICENTE, Pedro Miguel dos Santos Ferreira Vicente. Corporate Governance e Setor Empresarial Público em Portugal: Contributo para um normativo regulador. Mestrado em Gestão e Políticas Públicas. ISCSP. Lisboa. 2014 